\title{
Effect of long-term GH replacement therapy on cardiovascular outcomes in GH-deficient patients previously treated for acromegaly: a sub-analysis from the Dutch National Registry of Growth Hormone Treatment in Adults
}

Christa C van Bunderen, Nadège C van Varsseveld, Martijn W Heymans ${ }^{1}$, Anton A M Franken ${ }^{2}$, Hans P F Koppeschaar ${ }^{3}$, Aart J van der Lely ${ }^{4}$ and Madeleine L Drent

Section of Endocrinology, Department of Internal Medicine, Neuroscience Campus Amsterdam, VU University Medical Center, De Boelelaan 1117, 1081 HV Amsterdam, The Netherlands, 'Department of Epidemiology and Biostatistics, VU University Medical Center, Amsterdam, The Netherlands, ${ }^{2}$ Department of Internal Medicine, Isala Clinics, Zwolle, The Netherlands, ${ }^{3}$ Emotional Brain and Alan Turing Institute for Multidisciplinary Health Research, Almere, The Netherlands and ${ }^{4}$ Division of Endocrinology and Metabolism, Department of Internal Medicine, Erasmus Medical Center, Rotterdam, The Netherlands

Correspondence should be addressed to $\mathrm{C} C$ van Bunderen Email c.vanbunderen@vumc.nl

\begin{abstract}
Objective: The effect of GH deficiency (GHD) on the metabolic profile of acromegaly patients is unclear in patients previously treated for acromegaly, as are the efficacy and safety of GH treatment in this particular group. The aim of the study is to describe the characteristics of patients with severe GHD who were previously treated for acromegaly, and to investigate the effects of long-term GH treatment on cardiovascular risk factors and morbidity, compared with patients who were treated for a nonfunctioning pituitary adenoma (NFPA).
\end{abstract}

Design: A nationwide surveillance study.

Methods: Sixty-five patients from the Dutch National Registry of Growth Hormone Treatment in Adults with previous acromegaly were compared with 778 patients with previous NFPA. Cardiovascular indices, including body composition, lipid profile, glucose metabolism, blood pressure, and morbidity were investigated.

Results: GHD patients with previous acromegaly had an unfavorable metabolic profile comparable with or more than GHD patients with previous NFPA. GH treatment led to improvement of the lipid profile in both groups, also after excluding patients using lipid-lowering medication. In patients with previous acromegaly, $\mathrm{HbA1c}$ levels increased more than in patients with previous NFPA (estimate $0.03,95 \% \mathrm{Cl} 0.002-0.06, P=0.04$ ). The risk for developing cardiovascular diseases was not different between the groups.

Conclusions: The patients with GHD after previous acromegaly have an unfavorable metabolic profile comparable with patients with GHD after previous NFPA. In both groups, the lipid profile improves during GH treatment. Changes in glucose metabolism should be monitored closely. GH treatment in patients with GHD previously treated for acromegaly had no deleterious effect on cardiovascular morbidity. 


\section{Introduction}

Acromegaly is a serious disorder caused by chronic growth hormone (GH) excess and a subsequent hypersecretion of insulin-like growth factor 1 (IGF1), almost always due to a pituitary adenoma (1). The associations of raised GH and IGF1 concentrations with cardiovascular, cerebrovascular, and metabolic complications are described $(2,3)$. Therefore, the clinical and biochemical control of the disease is of crucial importance. A decrease in GH and IGF1 levels depending on the normal age and gender-adjusted range has been reported to lower the risk for cardiovascular diseases (CVD) (3). Transsphenoidal surgery is the treatment of choice for intrasellar microadenomas, noninvasive macroadenomas, and when the tumor is causing compression symptoms on the surrounding tissues $(4,5)$. Surgery or radiotherapy as treatment modalities may be burdened by a great prevalence of pituitary hormone deficiencies, including GH deficiency (GHD) (6). Ronchi et al. (6) stated that the prevalence of severe GHD is $60 \%$ in patients treated for acromegaly by surgery alone or surgery followed by radiotherapy.

GHD in adults is also increasingly recognized as an important (metabolic) syndrome (7). The associations of low IGF1 levels with cardiovascular risk factors, such as an adverse lipid profile, altered body composition with increased fat mass, and BMI, are reported $(7,8)$. Adults with untreated GHD have a decreased life expectancy due to an increased mortality from CVD $(9,10)$. Many studies have demonstrated positive effects of GH treatment on these cardiovascular risk factors in adults with GHD $(11,12)$, even up to a follow-up of 10 years $(13,14)$.

Only a few studies have investigated the characteristics of patients with GHD after treatment for GH hypersecretion and an unfavorable metabolic profile has been suggested $(15,16)$. GH treatment has been demonstrated to show improvement in the metabolic parameters in acromegalic patients with GHD $(17,18)$. However, contradicting results are also published (19), and longterm data are lacking. Norrman et al. (20) studied the effect of 2 years of GH treatment in ten patients with GHD, who were previously treated for acromegaly and found more vascular events during follow-up compared with matched patients treated for a nonfunctioning pituitary adenoma (NFPA). Whether the increased rate of vascular events was due to the impaired metabolic profile or other patient characteristics at baseline or due to GH treatment itself could not be defined and safety issues remain unresolved.
The aim of the present study, using data from the Dutch National Registry of GH Treatment in Adults, is to describe the characteristics of patients with severe GHD previously treated for acromegaly, and to study the safety and effects of long-term GH treatment with respect to cardiovascular outcomes, compared with patients with GHD who were treated for a NFPA.

\section{Subjects and methods}

\section{Study population}

The Dutch National Registry of GH Treatment in Adults was established in 1998 as an initiative of the Ministry of Health to gain insights into long-term efficacy, safety, and costs of GH treatment in The Netherlands. Approval by an independent board of endocrinologists was required for reimbursement of GH treatment by the health insurer, and a registry was linked to this assessment. Severe GHD was defined according to the consensus guidelines of the Growth Hormone Research Society (21). Up to 2009, a total of 2891 patients were registered. Their characteristics and diagnostic test procedures are described in more detail elsewhere (22). In this study, patients with severe GHD previously treated for acromegaly $(n=72)$ or NFPA $(n=887)$ were selected. The patients were excluded from the analyses if they had received GH treatment or had follow-up data $<30$ days, resulting in 65 and 778 patients respectively (Fig. 1). Patients lost to follow-up, who died, or stopped GH treatment were censored in the analysis. During GH treatment, 38 patients died (4.5\%) (one acromegaly patient (1.5\%) and 37 NFPA patients (4.8\%)). The reason for discontinuation of GH was related with CVD or the patient's metabolic profile in four of 132 cases in the total group.

\section{Measurements}

Data were collected retrospectively from the initiation of GH treatment and subsequently (bi-)annually from medical records by trained monitors. As an internal quality control, in $10 \%$ of patients, data were collected twice by different monitors. Person-years of treatment were calculated from the date of starting GH treatment in adulthood (baseline) until the last date of follow-up, discontinuation of $\mathrm{GH}$, or death. The dose of $\mathrm{GH}$ treatment was individualized by the attending physician with the common aim of normalizing IGF1 SDSs for age 


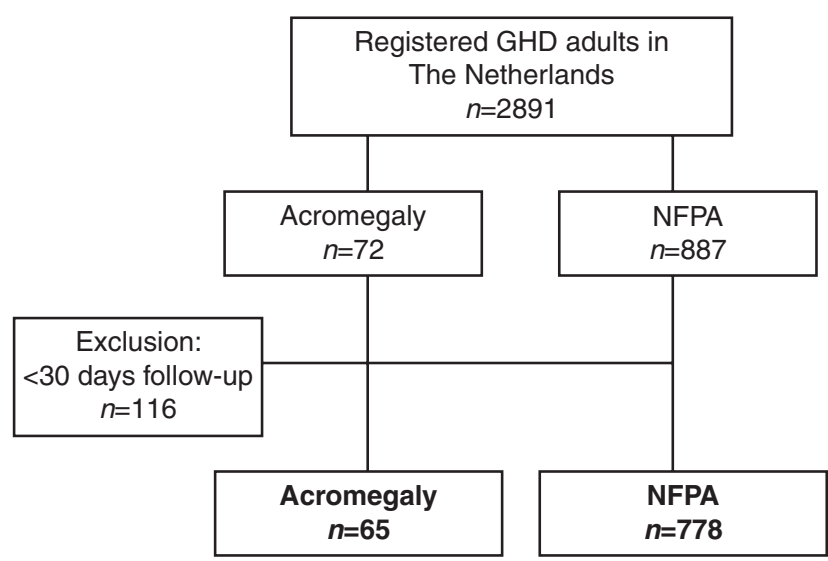

Figure 1

Design of study sample. GHD, growth hormone deficiency.

and gender. The use of lipid-lowering, antihypertensive, and antidiabetic medication was recorded at baseline, and during follow-up. Data on cardiovascular risk factors included in our analyses were BMI $\left(\mathrm{kg} / \mathrm{m}^{2}\right)$, waist circumference $(\mathrm{cm})$, and systolic and diastolic blood pressure $(\mathrm{mmHg})$. Measurements of total, HDL, LDL cholesterol, triglycerides (all expressed as $\mathrm{mmol} / \mathrm{l}$ ), and HbA1c levels (\%) were conducted locally by routine laboratory techniques. Medical history and adverse events were recorded thoroughly and (at least) coded for cardiac-related diseases (e.g. myocardial infarction, heart failure, and coronary interventions), arrhythmias (e.g. atrial fibrillation, ventricular tachycardia, and bundle branch blocks), peripheral arterial diseases (e.g. atherosclerosis, intermittent claudication, and vascular surgery), stroke, and diabetes mellitus. Date and cause of death were collected through medical records and death certification from the Dutch Central Bureau of Statistics, as described in more detail elsewhere (23).

\section{Statistical analyses}

Categorical data are expressed as number (\%) and continuous data as mean (s.D.) or median (interquartile range (IQR)) for skewed variables. Parametric (Student's $t$-test or $\chi^{2}$-test) or nonparametric (Mann-Whitney $U$ test) tests were used when appropriate. To estimate changes in the outcome measures over time, linear mixed models (LMMs) were used and time was included in these models as a continuous variable, i.e. the time points were different for each patient. Mixed models use all available data, properly accounting for the correlation between repeated measurements within patients over time. As recommended by Fitzmaurice et al. (24), we included the baseline values of risk factors in our LMMs as part of the outcome variable, to correctly handle missing baseline values. To study the increase or decrease in effect between the patients with previous acromegaly and NFPA over time, interaction terms between underlying diagnosis and time were introduced in all models. LMMs can handle missing data under the missing at random assumption, which we assumed for our missing data on cardiovascular risk factors. We checked the influence of the difference in available data during follow-up, i.e. with more or less follow-up measurements over time. This was done by first defining a drop-out variable with two categories. One group consisted of patients with followup measurements until less than the median follow-up time of the total group and another group of patients with more follow-up measurements. With this drop-out variable, we were able to test the difference in effect between the patients with previous acromegaly and NFPA that were accordingly defined by the categories of the drop-out variable. This was tested in the LMM by including a three-way-interaction term of underlying diagnosis, time, and the drop-out variable (25). No significant influence was demonstrated. The assumptions of the LMMs were checked by using residuals plots and by evaluating the residual variance over time. The analyses were carried out unadjusted, and adjusted for age and sex. Sensitivity analyses were carried out to account for the use of concomitant medication during follow-up. A Cox's proportional hazard model was used to evaluate the risk for developing CVD (including fatal and nonfatal cardiac diseases and stroke, arrhythmias, and peripheral arterial disease). Two sided $P$ values of 0.05 or less were considered significant. The statistical analyses were performed by the statistical software package IBM SPSS statistics 20.0 (SPSS, Inc.).

\section{Results}

\section{Baseline characteristics}

Patients with previous acromegaly were diagnosed with severe GHD based on a GH stimulation test in $94 \%$ of the cases $(52.5 \%$ insulin tolerance test, $24.6 \%$ GHRH/arginin test, and $22.9 \%$ other) and $90 \%$ in NFPA. In four cases (all NFPA), the diagnostic test was unknown. The remaining cases from both groups were diagnosed based on an IGF1 concentration $\leq 2$ s.D. for age and sex in combination with multiple pituitary hormone deficiencies. The 
Table 1 Baseline characteristics of GHD patients previously treated for acromegaly and nonfunctioning pituitary adenomas. Data are expressed as number (\%) unless specified otherwise.

\begin{tabular}{|c|c|c|c|}
\hline & Acromegaly & NFPA & $\boldsymbol{P}_{\text {value }}{ }^{\mathrm{a}}$ \\
\hline No. of patients & 65 & 778 & \\
\hline Age, year (S.D.) & $53.0(11.7)$ & $54.8(11.6)$ & 0.24 \\
\hline Sex, no. of females & $38(58.5)$ & 301 (38.7) & 0.002 \\
\hline Pituitary surgery & $59(90.8)$ & 729 (93.9) & 0.29 \\
\hline Cranial radiotherapy & $51(78.5)$ & $441(57.2)$ & 0.001 \\
\hline Time since treatment pituitary tumor ${ }^{\mathrm{b}}$, year (s.D.) & $14.8(12.9)$ & $3.5(8.1)$ & $<0.001$ \\
\hline \multicolumn{4}{|l|}{ Extent of pituitary insufficiency } \\
\hline Isolated GHD & $10(15.4)$ & $39(5.0)$ & 0.003 \\
\hline Adrenal insufficiency & $44(67.7)$ & 599 (77.0) & 0.09 \\
\hline Hypothyroidism & $47(72.3)$ & $625(80.3)$ & 0.12 \\
\hline Hypogonadism & $44(67.7)$ & $634(81.5)$ & 0.01 \\
\hline ADH deficiency & $4(6.2)$ & 105 (13.5) & 0.09 \\
\hline Prolactin deficiency & $1(1.5)$ & $5(0.6)$ & 0.38 \\
\hline \multicolumn{4}{|l|}{ Medical history } \\
\hline Cardiac disease & $8(12.3)$ & $93(12.2)$ & 0.98 \\
\hline Arrhythmias & $0(0.0)$ & $35(4.6)$ & 0.10 \\
\hline Peripheral arterial disease & $3(4.6)$ & $25(3.3)$ & 0.48 \\
\hline Stroke & $7(10.8)$ & $43(5.6)$ & 0.10 \\
\hline Diabetes mellitus & $1(1.5)$ & $62(8.1)$ & 0.05 \\
\hline
\end{tabular}

NFPA, nonfunctioning pituitary adenoma; GH, growth hormone; GHD, growth hormone deficiency; ADH, antidiuretic hormone. ${ }^{a}$ Continuous variables were compared by Student's $t$-test, categorical variables by $\chi^{2}$-test.

${ }^{\mathrm{b}}$ Time from surgery or primary radiotherapy for the pituitary adenoma or first confirming MRI when no surgery or radiotherapy was initiated until start of $\mathrm{GH}$ treatment.

patients' characteristics of both groups are given in Table 1 . The patients with previous acromegaly included more women, more patients with isolated GHD, and more patients who received cranial radiotherapy. The time between the treatment of the pituitary adenoma and start of GH treatment was longer in patients with previous acromegaly than previous NFPA. The metabolic profile in both groups are given in Table 2; waist circumference in men, diastolic blood pressure, and LDL cholesterol were significantly higher in previous acromegaly patients compared with patients with previous NFPA. In patients with a previous NFPA, a higher $\mathrm{Hb} 1 \mathrm{Ac}$ was found. The use of lipid-lowering medication was equally divided between the groups (15.6 vs $16.3 \%$, $P=0.90$ ) and previous acromegaly patients tended to use more antihypertensive medication (35.9 vs $25.8 \%$, $P=0.08$ )

\section{Long-term follow-up}

The median follow-up for patients previously treated for acromegaly was 3.1 year (IQR 6.4), corresponding with 280 treatment-years. In patients previously treated for NFPA, the median follow-up was 5.2 year (IQR 6.6), which reflects 4391 treatment-years. GH dose, gender and use of oral estrogens, was not significantly different between the groups (0.28 $\mathrm{mg}$ vs $0.27 \mathrm{mg} /$ day). During follow-up, the use of lipid-lowering medication was equally divided between groups (34.4 vs $35.7 \%$ ), as was the use of antihypertensive medication (50 vs $44.3 \%$ ); however, the duration of follow-up differed.

Table 2 Baseline characteristics of cardiovascular risk factors for GHD patients previously treated for acromegaly and nonfunctioning pituitary adenomas. Data are expressed as mean (s.D.) unless specified otherwise. Waist and HDL cholesterol level are demonstrated stratified by gender due genderspecific normal values.

\begin{tabular}{|c|c|c|c|}
\hline & Acromegaly & NFPA & $P$ value $^{a}$ \\
\hline BMI $\left(\mathrm{kg} / \mathrm{m}^{2}\right)$ & $29.6(5.7)$ & $28.6(4.8)$ & 0.23 \\
\hline \multicolumn{4}{|l|}{ Waist circumference $(\mathrm{cm})$} \\
\hline Male & $111.2(13.3)$ & $101.5(10.0)$ & 0.004 \\
\hline Female & $96.0(12.9)$ & $98.7(13.2)$ & 0.46 \\
\hline $\begin{array}{l}\text { Systolic blood pressure } \\
(\mathrm{mmHg})\end{array}$ & $136(17)$ & $136(19)$ & 0.91 \\
\hline $\begin{array}{l}\text { Diastolic blood pressure } \\
(\mathrm{mmHg})\end{array}$ & $86(11)$ & $83(10)$ & 0.02 \\
\hline Total cholesterol $(\mathrm{mmol} / \mathrm{l})$ & $6.16(1.01)$ & $5.83(1.28)$ & 0.08 \\
\hline \multicolumn{4}{|l|}{ HDL cholesterol ( $\mathrm{mmol} / \mathrm{l})$} \\
\hline Male & $1.27(0.42)$ & $1.11(0.32)$ & 0.09 \\
\hline Female & $1.56(0.67)$ & $1.42(0.45)$ & 0.32 \\
\hline LDL cholesterol $(\mathrm{mmol} / \mathrm{l})$ & $4.10(1.01)$ & $3.47(1.14)$ & 0.01 \\
\hline Triglycerides $(\mathrm{mmol} / \mathrm{l})^{\mathrm{b}}$ & $1.52(1.34)$ & $1.79(1.21)$ & 0.25 \\
\hline $\mathrm{HbA} 1 \mathrm{c}(\%)$ & $5.3(0.5)$ & $5.7(0.8)$ & $<0.001$ \\
\hline
\end{tabular}

NFPA, nonfunctioning pituitary adenoma.

${ }^{a}$ Normally distributed variables were compared by Student's $t$-test, skewed variables by Mann-Whitney $U$ test.

${ }^{\mathrm{b}}$ Median (IQR). 


\section{Effect of long-term GH treatment on cardiovascular risk factors}

Table 3 gives the estimates of change in the different cardiovascular risk factors during GH treatment for both patients with previous acromegaly and NFPA and the estimated difference between both groups. In patients with previous NFPA, an increase in waist circumference and a positive effect of GH treatment on diastolic blood pressure and lipid profile were observed. In patients with previous acromegaly, the decrease in diastolic blood pressure, total cholesterol, and LDL cholesterol was shown to be significanct. The decrease in LDL cholesterol was significantly more pronounced in patients with previous acromegaly than in patients with previous NFPA. Adjusting for age and sex did not significantly change these outcomes. Exclusion of patients on antihypertensive medication resulted in loss of the encountered positive effect on blood pressure. After excluding patients who use lipid-lowering medication, the positive effect of GH treatment on the lipid profile remained significant in both groups. However, the difference in effect on the lipid profile between the two groups was no longer significant. After excluding patients on antidiabetic medication, the difference in increases of HbA1c levels between the groups became significant, showing higher elevations in patients with previous acromegaly (estimate $0.03,95 \%$ CI 0.002-0.06, $P=0.04$ ).

\section{Effect of long-term GH treatment on cardiovascular mortality and morbidity}

CVD was the cause of death in one patient with previous acromegaly (50-year-old men with hypertension and angina pectoris diagnosed before start of GH treatment died from ischemic heart disease 3.8 years after start of GH therapy), and in 11 patients with previous NFPA (age range: 53-77 year, six cases of stroke and five of CVD, ranging from 0.4 to 9.9 years after start of GH therapy). After excluding patients with a positive medical history for CVD $(n=167)$, or unknown data on adverse events $(n=2)$, two patients with previous acromegaly (3.8\%) and 69 patients with previous NFPA (11.3\%) developed CVD (including fatal and nonfatal cardiac diseases and stroke, arrhythmias, and peripheral arterial disease). The risk of CVD was not significantly different for patients with previous acromegaly compared with previous NFPA during GH treatment (hazard ratio 0.44 (95\% CI 0.11 $1.81), P=0.26)$. In the group of patients with previous acromegaly, one patient (1.7\%) had developed stroke (in combination with atrial fibrillation) compared with 37 (5.2\%) patients with previous NFPA. The patient with stroke and previous acromegaly had received cranial radiotherapy in the past, as did 29 of the 37 patients with stroke and previous NFPA. No patient with previous acromegaly developed diabetes mellitus, compared with 50 patients $(7.2 \%)$ with previous NFPA.

\section{Discussion}

Both GH hypersecretion and GHD have been reported to be associated with increased cardiovascular morbidity and mortality. Treatment of acromegaly demonstrated to reduce this elevated risk. In this observational study, we describe the characteristics of patients with severe GHD who were previously treated for acromegaly and studied the safety and effect of long-term GH treatment on cardiovascular risk factors and morbidity, compared

Table 3 Estimates of change over time analyzed by linear mixed models for GHD patients previously treated for acromegaly and nonfunctioning pituitary adenomas during $\mathrm{GH}$ treatment. Values are estimates of change over time per year $(95 \% \mathrm{Cl})$.

\begin{tabular}{|c|c|c|}
\hline & \multicolumn{2}{|l|}{ Acromegaly } \\
\hline & Estimate $(95 \% \mathrm{Cl})$ & $P$ value \\
\hline BMI $\left(\mathrm{kg} / \mathrm{m}^{2}\right)$ & $0.07(-0.06 ; 0.20)$ & 0.26 \\
\hline Waist circumference $(\mathrm{cm})$ & $0.31(-0.20 ; 0.82)$ & 0.24 \\
\hline Systolic blood pressure $(\mathrm{mmHg})$ & $-0.45(-1.22 ; 0.31)$ & 0.25 \\
\hline Diastolic blood pressure $(\mathrm{mmHg})$ & $-0.59(-1.02 ;-0.15)$ & 0.01 \\
\hline Total cholesterol (mmol/l) & $-0.15(-0.20 ;-0.09)$ & $<0.001$ \\
\hline HDL cholesterol (mmol/l) & $0.01(-0.01 ; 0.02)$ & 0.29 \\
\hline LDL cholesterol $(\mathrm{mmol} / \mathrm{l})$ & $-0.16(-0.22 ;-0.10)$ & $<0.001$ \\
\hline Triglycerides (mmol/l) & $-0.03(-0.09 ; 0.02)$ & 0.22 \\
\hline $\mathrm{HbA} 1 \mathrm{c}(\%)$ & $0.03(-0.01 ; 0.07)$ & 0.10 \\
\hline
\end{tabular}

\begin{tabular}{ccc}
\hline \multicolumn{1}{c}{ NFPA } & \\
\hline Estimate $(95 \% \mathrm{Cl})$ & & $P$ value \\
\cline { 1 - 1 } $0.03(-0.004 ; 0.06)$ & & 0.08 \\
$0.19(0.06 ; 0.31)$ & & 0.004 \\
$-0.19(-0.40 ; 0.02)$ & & 0.07 \\
$-0.28(-0.40 ;-0.16)$ & $<0.001$ \\
$-0.09(-0.11 ;-0.08)$ & $<0.001$ \\
$0.02(0.01 ; 0.02)$ & $<0.001$ \\
$-0.07(-0.09 ;-0.05)$ & $<0.001$ \\
$-0.04(-0.05 ;-0.02)$ & $<0.001$ \\
$0.01(-0.002 ; 0.02)$ & 0.13 \\
\hline
\end{tabular}

\begin{tabular}{|c|c|}
\hline \multicolumn{2}{|c|}{ Acromegaly vs NFPA } \\
\hline Estimate $(95 \% \mathrm{Cl})^{\mathrm{a}}$ & $P$ value \\
\hline $0.04(-0.09 ; 0.18)$ & 0.51 \\
\hline $0.12(-0.42 ; 0.64)$ & 0.65 \\
\hline$-0.26(-1.06 ; 0.53)$ & 0.52 \\
\hline$-0.31(-0.76 ; 0.14)$ & 0.18 \\
\hline$-0.06(-0.11 ; 0.002)$ & 0.06 \\
\hline$-0.01(-0.02 ; 0.01)$ & 0.34 \\
\hline$-0.09(-0.15 ;-0.02)$ & 0.01 \\
\hline $0.002(-0.05 ; 0.06)$ & 0.95 \\
\hline $0.02(-0.02 ; 0.06)$ & 0.24 \\
\hline
\end{tabular}

NFPA, nonfunctioning pituitary adenoma.

${ }^{a}$ Estimate of the interaction term between time and group to estimate the difference in effect of GH treatment over time between patients previously treated for acromegaly compared with nonfunctioning pituitary adenomas. 
with GHD patients treated for a NFPA. At baseline, GHD patients with previous acromegaly had an unfavorable metabolic profile, comparable to or worse than GHD patients who were previously treated for NFPA. However, HbA1c level was significantly higher in GHD patients treated for NFPA. GH treatment led to a significant improvement in the lipid profile in both groups, even after excluding patients using lipid-lowering medication. After excluding patients using antidiabetic medication, in patients with previous acromegaly HbA1c level increased significantly more than in patients with previous NFPA. GH treatment in patients who were previously treated for acromegaly demonstrated no deleterious effect on cardiovascular morbidity.

To date, ten studies (Table 4) investigated the characteristics of GHD and/or the effect of GH treatment on cardiovascular outcome measures in GHD patients after treatment for acromegaly $(6,15,16,17,18,19,20$, $26,27,28)$. In three studies, patients who were $\mathrm{GH}$ sufficient after treatment for acromegaly or active acromegaly were used as controls. These studies demonstrated that GHD after treatment for acromegaly is associated with a more impaired metabolic profile $(15,16,27)$. Studies using GHD of other etiologies or after treatment for a NFPA as comparator demonstrated no differences in clinical presentation $(6,17,26)$. However, Norrman et al. (20) reported higher LDL cholesterol in GHD after treatment for acromegaly, and Tritos et al. (28) reported lower total and LDL cholesterol and a higher waist circumference, compared with patients with previous NFPA. In an observational (KIMS) study on GH replacement, a higher prevalence of stroke was reported at baseline; however, the group with previous acromegaly harbored more subjects who received cranial radiotherapy in the past (26). Six studies investigated the effect of GH treatment in GHD after acromegaly $(17,18,19,20,26,28)$, with only one randomized placebo-controlled trial (18). Positive effects of GH treatment on body composition and lipid profile have been reported $(17,18,20,28)$. The study by both van der Klaauw et al. (19) and the Pfizer-owned KIMS database (26) demonstrated no significant effect on cardiovascular risk factors after 6 and 12 months. When the effect of GH treatment was compared with GHD due to a collection of other etiologies or NFPA, a similar (positive) effect was found $(17,20,26,28)$. Norrman et al. (20) described a higher number of vascular events during the 2 years of follow-up compared with patients with a previous NFPA (3 vs 0). Tritos et al. (28) did not find a difference in the incidence of CVD between patients with previous acromegaly and NFPA. However, they found an increased standardized mortality ratio (SMR) for cardiovascular mortality rate in patients with previous acromegaly compared with patients with previous NFPA and with the general population. The other two comparative studies investigating $\mathrm{GH}$ treatment in patients treated for acromegaly did not show a higher incidence of cardiovascular events compared with $\mathrm{GH}$ treatment in other etiologies of GHD $(17,26)$.

This study observed some differences between patients with previous acromegaly and NFPA at baseline. The group of patients with previous acromegaly contained more women. NFPA is known to be more prevalent in men (29), but $58.5 \%$ women with previous acromegaly is rather high, to our opinion, as the prevalence of acromegaly has been reported to be equally divided between men and women $(1,30)$. However, also the observational studies from the KIMS Study Group included more women with previous acromegaly $(26,28)$. Perhaps women are more vulnerable for GHD after treatment of acromegaly and are therefore more often included in observational studies on GH treatment. Next, there was a striking difference in time between treatment of the pituitary tumor and start of $\mathrm{GH}$ between the two groups. The delay in diagnosing GHD after treatment for the pituitary tumor is probably overestimated due to the actual year of treatment, which was 1987 for patients with acromegaly and 1996 for patients with a NFPA (data not shown), and the fact that diagnosing and treating GHD became a clinical practice in The Netherlands after 1995 (22). However, a difference in the duration of untreated GHD can not be ruled out. This could have affected the differences in metabolic parameters as observed at baseline. Patients with previous acromegaly exhibited a worse metabolic profile with respect to waist circumference in men, diastolic blood pressure, and LDL cholesterol. Active acromegaly is also known for an increased prevalence of cardiovascular risk factors, including hypertension, compared with healthy controls (3). The reported data on lipids in acromegaly are controversial (30). Decreased levels of total, LDL, and HDL cholesterol are reported (3). Similar to the study by Norrman et al. (20), we found higher levels of LDL cholesterol in patients with previous acromegaly compared with previous NFPA. Perhaps this is an effect of the untreated GHD mentioned earlier. At baseline, our group of patients with GHD after acromegaly exhibited lower HbA1c levels and less diabetes mellitus. This is unexpected because active acromegaly is related with insulin resistance and diabetes mellitus is more prevalent in patients with active acromegaly than in the general population (3). Selection bias in our cohort might be the 


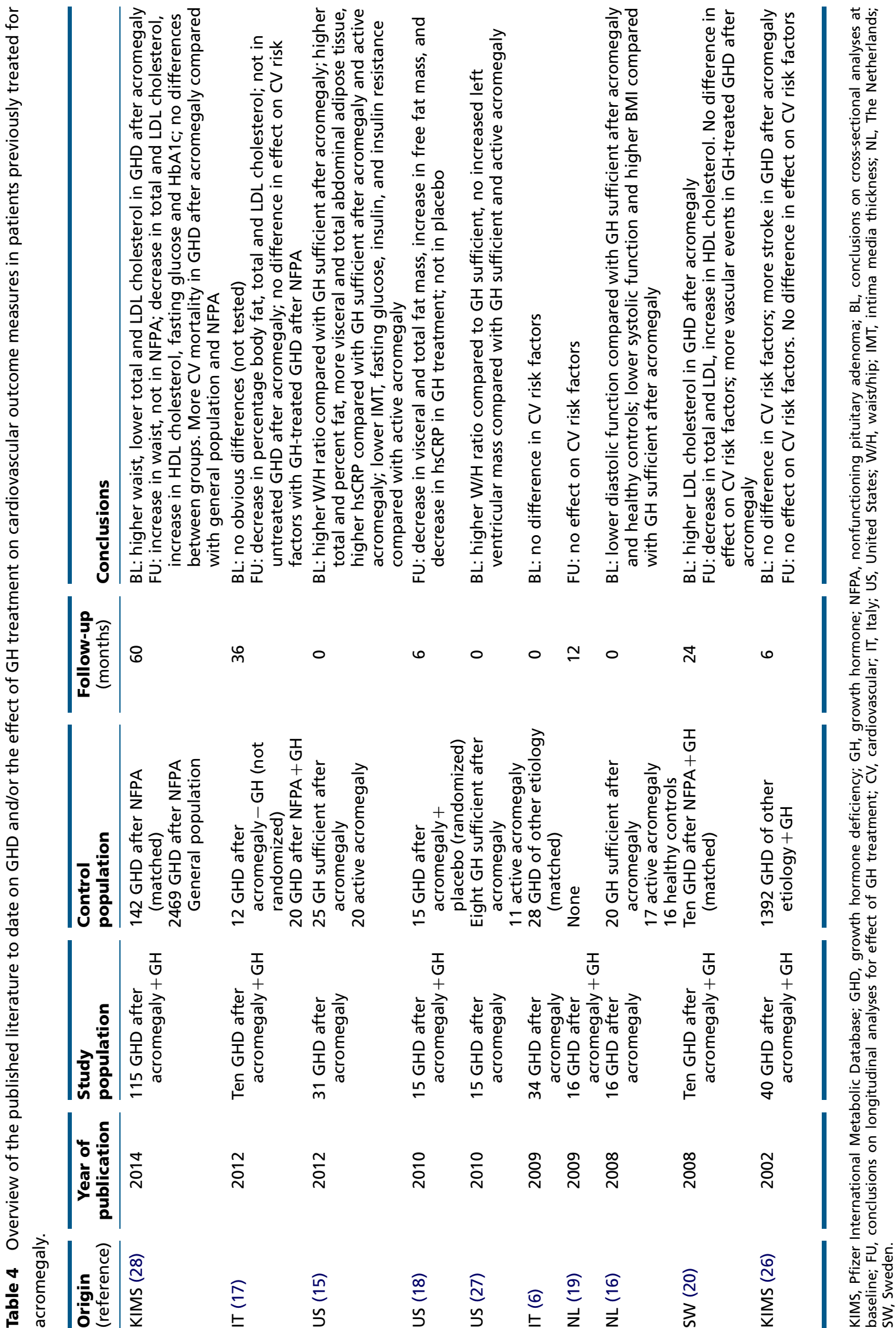


reason for this discrepancy. Mainly, patients with GHD and the intention to initiate GH treatment were registered in our database and patients with impaired glucose metabolism or diabetes mellitus might be detained from GH treatment by their attending physician. However, this could also have been the case in patients with previous NFPA. In addition, it should be noticed that patients with previous NFPA had more ACTH insufficiency necessitating glucocorticoid substitution therapy which, if supraphysiologically dosed, might lead to an hyperglycemic condition (31). More stroke tended to occur in patients previously treated for acromegaly $(P=0.10)$. However, this group had received more cranial radiotherapy which could lead to radiationinduced angiopathy (32). Previously, cranial radiotherapy is demonstrated to be a predictor for cerebrovascular mortality in hypopituitary patients (33).

During follow-up, despite an increase in waist circumference (especially in previous NFPA), the positive effect of GH treatment on lipid profile was evident in both groups. These positive effects of long-term GH treatment in all GHD patients on lipid profile have been demonstrated before, except for triglycerides for which results remain inconclusive $(34,35)$, also in patients with GHD after acromegaly positive effects have been reported $(17,20,28)$. However, most studies do not or are unable to take into account the use of lipid-lowering medication. After excluding patients using lipid-lowering medication in our study, the positive effect on lipid profile remained significant. There was no difference in effect between patients with previous acromegaly or NFPA. After excluding patients using antidiabetic medications, there was a difference in changes in HbA1c level over time. HbA1c level in patients with previous acromegaly seemed to increase more than in patients with previous NFPA. Both acromegaly and GH treatment are described to induce insulin resistance $(11,30)$. After treatment for acromegaly, the characteristic of insulin insensitive state for active acromegaly obviously does not recover, suggesting either a persistently increased pancreatic islet $\beta$-cell mass and/or peripheral insulin resistance $(30,36,37)$. This might have primed patients with previous acromegaly for a steeper increase in HbA1c levels during GH treatment than patients with previous NFPA. After excluding patients using antihypertensive medication, the positive effect on (diastolic) blood pressure disappeared. A positive effect of GH treatment on blood pressure in both groups does not seem compelling.

During follow-up of patients with previous acromegaly, no increased risk for developing fatal or nonfatal CVD was observed. Norrman et al. (20) were the first to raise questions about safety of GH treatment in patients previously treated for acromegaly. They described three vascular events during a 2-year follow-up period of ten patients with previous acromegaly while no events in patients with previous NFPA were recorded. Two of the three events were cerebrovascular infarctions 2 and 3 weeks after start of $\mathrm{GH}$ treatment and both patients had received cranial radiotherapy. However, whether the increased rate of vascular events was due to the impaired metabolic profile or other patient characteristics at baseline or due to GH treatment itself could not be addressed properly due to the small study population and relatively short follow-up in that study. Thereafter, this safety concern is restated by others, but could not be verified or retested $(17,18)$. Recently, Tritos et al. $(28)$ have found a comparable safety profile in patients with previous acromegaly and NFPA, with the exception of an elevated cardiovascular mortality rate. Taking into account the low number of events in this present study, we carefully conclude that GH treatment does not seem to have a deleterious effect on cardiovascular morbidity in patients previously treated for acromegaly. Due to the low number of events, we were unable to solely look at cardiovascular mortality rates in this study which would have been desirable. A previous study from the Dutch National Registry of GH Treatment in Adults investigated all-cause mortality in GHD patients treated with GH and reported no increased SMR for patients with previous GH- and ACTH-secreting (SMR 1.10, 95\% CI 0.55-2.20) or NFPAs (SMR 0.90, 95\% CI 0.66-1.25) (23). Taking GH- and ACTHsecreting adenomas together in these analyses could lead to an overestimation of the mortality ratio in acromegaly. Therefore, one might conclude that all-cause mortality was not increased in these patients. The KIMS Study Group has also investigated all-cause mortality in different etiologies of GHD and found an SMR of 1.46 (95\% CI $0.85-2.34$ ) in 239 patients with previous acromegaly (38). With only one patient with a CVD as cause of death in our study population with previous acromegaly, cardiovascular mortality does not seem to be elevated. However, sample size is still limited. Next to that, one should not overlook the fact that patients in observational studies were selected by their attending physician to receive GH and potential selection bias should be considered when interpreting these results.

This is the fourth study on the effect of GH treatment in patients previously treated for acromegaly compared with previous NFPA $(17,20,28)$. Despite the observational nature of our study, we describe a larger population with a long follow-up period, and due to a sophisticated method 
of longitudinal data-analysis, able to deal properly with missing data, loss of power was averted. In our study, through (bi-)annual monitoring of patient's medical records by trained monitors, thorough registration of adverse events and medication use during follow-up was ensured. This made it possible to account for the use of cardioprotective medication, which is often overlooked in other reports, and to study (cardiovascular) morbidity. However, few limitations have to be addressed. Despite the homogeneous nature of the studied etiologies of GHD, there are clinical characteristics that might have influenced the presented results. For instance, the higher prevalence of multiple pituitary hormone deficiencies in patients with previous NFPA compared with acromegaly might result in an underestimation of the metabolic differences at baseline between the groups. However, we believe that during follow-up the influence of this characteristic is limited (39). Another issue is the diversity of incorporated laboratory methodologies used, which could influence betweengroup and within-individual analyses. Also, the collection of blood samples for triglycerides in a fasting state could not be verified in all cases. However, the distribution of these influencing factors are probably at random, so the overall effects of these issues on the described results, at least for between-group analyses, will be small.

In conclusion, this study demonstrates that patients with GHD after treatment for acromegaly have an unfavorable metabolic profile, and benefit from $\mathrm{GH}$ treatment with respect to lipid profile, similar to patients with previous NFPA. Changes in glucose metabolism should be monitored closely during treatment. GH treatment for GHD in patients previously treated for acromegaly demonstrated no deleterious effect on cardiovascular morbidity.

\section{Declaration of interest}

The authors declare that there is no conflict of interest that could be perceived as prejudicing the impartiality of the research reported.

\section{Funding}

C C van Bunderen is supported by an AGIKO grant of The Netherlands Organisation for Health Research and Development (ZonMw) (grant number 92003591). Establishing the Dutch National Registry of GH Treatment in Adults was financed by the Health Care Insurance Board. This research did not receive any specific grant from any funding agency in the public, commercial or not-for-profit sector.

\section{Acknowledgements}

The authors are very grateful to all colleagues at the Internal and Endocrine departments of all participating Dutch hospitals for their collaboration.

\section{References}

1 Melmed S. Acromegaly pathogenesis and treatment. Journal of Clinical Investigation 2009119 3189-3202. (doi:10.1172/JCI39375)

2 Jayasena CN, Comninos AN, Clarke H, Donaldson M, Meeran K \& Dhillo WS. The effects of long-term growth hormone and insulin-like growth factor-1 exposure on the development of cardiovascular, cerebrovascular and metabolic co-morbidities in treated patients with acromegaly. Clinical Endocrinology 201175 220-225. (doi:10.1111/ j.1365-2265.2011.04019.x)

3 Berg C, Petersenn S, Lahner H, Herrmann BL, Buchfelder M, Droste M, Stalla GK, Strasburger CJ, Roggenbuck U, Lehmann N et al. Cardiovascular risk factors in patients with uncontrolled and long-term acromegaly: comparison with matched data from the general population and the effect of disease control. Journal of Clinical Endocrinology and Metabolism 201095 3648-3656. (doi:10.1210/jc.2009-2570)

4 Melmed S, Colao A, Barkan A, Molitch M, Grossman AB, Kleinberg D, Clemmons D, Chanson P, Laws E, Schlechte J et al. Guidelines for acromegaly management: an update. Journal of Clinical Endocrinology and Metabolism 200994 1509-1517. (doi:10.1210/jc.2008-2421)

5 van Bunderen CC, van Varsseveld NC, Baayen JC, van Furth WR, Aliaga ES, Hazewinkel MJ, Majoie CB, Freling NJ, Lips P, Fliers E et al. Predictors of endoscopic transsphenoidal surgery outcome in acromegaly: patient and tumor characteristics evaluated by magnetic resonance imaging. Pituitary 201316 158-167. (doi:10.1007/s11102-012-0395-7)

6 Ronchi CL, Giavoli C, Ferrante E, Verrua E, Bergamaschi S, Ferrari DI, Corbetta S, Montefusco L, Arosio M, Ambrosi B et al. Prevalence of GH deficiency in cured acromegalic patients: impact of different previous treatments. European Journal of Endocrinology 2009161 37-42. (doi:10.1530/EJE-09-0222)

7 de Boer H, Blok GJ \& Van der Veen EA. Clinical aspects of growth hormone deficiency in adults. Endocrine Reviews 199516 63-86. (doi:10.1210/er.16.1.63)

8 Cuneo RC, Salomon F, McGauley GA \& Sonksen PH. The growth hormone deficiency syndrome in adults. Clinical Endocrinology 199237 387-397. (doi:10.1111/j.1365-2265.1992.tb02347.x)

9 Rosèn T \& Bengtsson BA. Premature mortality due to cardiovascular disease in hypopituitarism. Lancet 1990336 285-288. (doi:10.1016/ 0140-6736(90)91812-O)

10 Stochholm K, Gravholt CH, Laursen T, Laurberg P, Andersen M, Kristensen LO, Feldt-Rasmussen U, Christiansen JS, Frydenberg M \& Green A. Mortality and GH deficiency: a nationwide study. European Journal of Endocrinology 2007 157 9-18. (doi:10.1530/EJE-07-0013)

11 Maison P, Griffin S, Nicoue-Beglah M, Haddad N, Balkau B \& Chanson P. Impact of growth hormone $(\mathrm{GH})$ treatment on cardiovascular risk factors in GH-deficient adults: a Metaanalysis of Blinded, Randomized, Placebo-Controlled Trials. Journal of Clinical Endocrinology and Metabolism 200489 2192-2199. (doi:10.1210/jc.2003-030840)

12 Salomon F, Cuneo RC, Hesp R \& Sonksen PH. The effects of treatment with recombinant human growth hormone on body composition and metabolism in adults with growth hormone deficiency. New England Journal of Medicine 1989321 1797-1803. (doi:10.1056/NEJM19891228 3212605)

13 Gibney J, Wallace JD, Spinks T, Schnorr L, Ranicar A, Cuneo RC, Lockhart S, Burnand KG, Salomon F, Sonksen PH et al. The effects of 10 years of recombinant human growth hormone $(\mathrm{GH})$ in adult GH-deficient patients. Journal of Clinical Endocrinology and Metabolism 199984 2596-2602. (doi:10.1210/jcem.84.8.5916)

14 Gotherstrom G, Bengtsson BA, Bosaeus I, Johannsson G \& Svensson J. A 10-year, prospective study of the metabolic effects of growth hormone replacement in adults. Journal of Clinical Endocrinology and Metabolism 200792 1442-1445. (doi:10.1210/jc.2006-1487)

15 Lin E, Wexler TL, Nachtigall L, Tritos N, Swearingen B, Hemphill L, Loeffler J, Biller BM, Klibanski A \& Miller KK. Effects of growth hormone deficiency on body composition and biomarkers of cardiovascular risk 
after definitive therapy for acromegaly. Clinical Endocrinology 201277 430-438. (doi:10.1111/j.1365-2265.2012.04361.x)

16 van der Klaauw AA, Bax JJ, Bleeker GB, Holman ER, Delgado V, Smit JW, Romijn JA \& Pereira AM. Cardiac manifestations of GH deficiency after treatment for acromegaly: a comparison to patients with biochemical remission and controls. European Journal of Endocrinology 2008159 705-712. (doi:10.1530/EJE-08-0496)

17 Giavoli C, Profka E, Verrua E, Ronchi CL, Ferrante E, Bergamaschi S, Sala E, Malchiodi E, Lania AG, Arosio M et al. GH replacement improves quality of life and metabolic parameters in cured acromegalic patients with growth hormone deficiency. Journal of Clinical Endocrinology and Metabolism 201297 3983-3988. (doi:10.1210/jc.2012-2477)

18 Miller KK, Wexler T, Fazeli P, Gunnell L, Graham GJ, Beauregard C, Hemphill L, Nachtigall L, Loeffler J, Swearingen B et al. Growth hormone deficiency after treatment of acromegaly: a randomized, placebo-controlled study of growth hormone replacement. Journal of Clinical Endocrinology and Metabolism 201095 567-577. (doi:10.1210/jc.2009-1611)

19 van der Klaauw AA, Bax JJ, Roelfsema F, Stokkel MP, Bleeker GB, Biermasz NR, Smit JW, Romijn JA \& Pereira AM. Limited effects of growth hormone replacement in patients with GH deficiency during long-term cure of acromegaly. Pituitary 200912 339-346. (doi:10.1007/s11102-0090186-y)

20 Norrman LL, Johannsson G, Sunnerhagen KS \& Svensson J. Baseline characteristics and the effects of two years of growth hormone (GH) replacement therapy in adults with GH deficiency previously treated for acromegaly. Journal of Clinical Endocrinology and Metabolism 200893 2531-2538. (doi:10.1210/jc.2007-2673)

21 Consensus guidelines for the diagnosis and treatment of adults with growth hormone deficiency: summary statement of the Growth Hormone Research Society Workshop on Adult Growth Hormone Deficiency. Journal of Clinical Endocrinology and Metabolism 199883 379-381. (doi:10.1210/jcem.83.2.4611)

22 van Nieuwpoort IC, van Bunderen CC, Arwert LI, Franken AA, Koppeschaar HP, van der Lely AJ, Twisk J, Boers M \& Drent ML. Dutch National Registry of Growth Hormone Treatment in Adults: patient characteristics and diagnostic test procedures. European Journal of Endocrinology 2011164 491-497. (doi:10.1530/EJE-10-0914)

23 van Bunderen CC, van Nieuwpoort IC, Arwert LI, Heymans MW, Franken AA, Koppeschaar HP, van der Lely AJ \& Drent ML. Does growth hormone replacement therapy reduce mortality in adults with growth hormone deficiency? Data from the Dutch National Registry of growth hormone treatment in adults. Journal of Clinical Endocrinology and Metabolism 201196 3151-3159. (doi:10.1210/jc.2011-1215)

24 Fitzmaurice GM, Laird NM \& Ware JH. Applied Longitudinal Analysis, 2nd edn. Hoboken, New Jersey: John Wiley \& Sons, Inc., 2011.

25 Hedeker D \& Gibbons RD. Application of random-effects patternmixture models for missing data in longitudinal studies. Psychological Methods 19972 64-78. (doi:10.1037/1082-989X.2.1.64)

26 Feldt-Rasmussen U, Abs R, Bengtsson BA, Bennmarker H, Bramnert M, Hernberg-Stahl E, Monson JP, Westberg B, Wilton P \& Wuster C. Growth hormone deficiency and replacement in hypopituitary patients previously treated for acromegaly or Cushing's disease. European Journal of Endocrinology 2002146 67-74. (doi:10.1530/eje.0.1460067)

27 Wexler TL, Durst R, McCarty D, Picard MH, Gunnell L, Omer Z, Fazeli P, Miller KK \& Klibanski A. Growth hormone status predicts left ventricular mass in patients after cure of acromegaly. Growth Hormone \& IGF Research 201020 333-337. (doi:10.1016/j.ghir.2010.05.003)

28 Tritos NA, Johannsson G, Korbonits M, Miller KK, Feldt-Rasmussen U, Yuen KC, King D, Mattsson AF, Jonsson PJ, Koltowska-Haggstrom M et al. Effects of long-term growth hormone replacement in adults with growth hormone deficiency following cure of acromegaly: a KIMS analysis. Journal of Clinical Endocrinology and Metabolism 201499 2018-2029. (doi:10.1210/jc.2014-1013)

29 Nielsen EH, Lindholm J, Laurberg P, Bjerre P, Christiansen JS, Hagen C, Juul S, Jorgensen J, Kruse A \& Stochholm K. Nonfunctioning pituitary adenoma: incidence, causes of death and quality of life in relation to pituitary function. Pituitary 2007 10 67-73. (doi:10.1007/s11102-007-0018-x)

30 Colao A, Ferone D, Marzullo P \& Lombardi G. Systemic complications of acromegaly: epidemiology, pathogenesis, and management. Endocrine Reviews 200425 102-152. (doi:10.1210/er.2002-0022)

31 Clore JN \& Thurby-Hay L. Glucocorticoid-induced hyperglycemia. Endocrine Practice 200915 469-474. (doi:10.4158/EP08331.RAR)

32 Murros KE \& Toole JF. The effect of radiation on carotid arteries. A review article. Archives of Neurology 198946 449-455. (doi:10.1001/ archneur.1989.00520400109029)

33 Bülow B, Hagmar L, Mikoczy Z, Nordstrom CH \& Erfurth EM. Increased cerebrovascular mortality in patients with hypopituitarism. Clinical Endocrinology 199746 75-81. (doi:10.1046/j.1365-2265.1997.d011749.x)

34 Appelman-Dijkstra NM, Claessen KM, Roelfsema F, Pereira AM \& Biermasz NR. Therapy of Endocrine Disease: Long-term effects of recombinant human GH replacement in adults with GH deficiency: a systematic review. European Journal of Endocrinology 2013169 R1-R14. (doi:10.1530/EJE-12-1088)

35 Gazzaruso C, Gola M, Karamouzis I, Giubbini R \& Giustina A. Cardiovascular risk in adult patients with growth hormone (GH) deficiency and following substitution with GH - an update. Journal of Clinical Endocrinology and Metabolism 201499 18-29. (doi:10.1210/jc.2013-2394)

36 Roelfsema F, Frolich M, Geelhoed-Duyvestijn PH, Nieuwenhuijzen Kruseman AC \& Looij BJ. Glucagon-stimulated plasma C-peptide and insulin levels in active and non-active acromegalics. Clinical Endocrinology 198523 627-634. (doi:10.1111/j.1365-2265.1985. tb01123.x)

37 Riedl M, Ludvik B, Pacini G, Clodi M, Kotzmann H, Wagner O, KautzkyWiller A, Prager R \& Luger A. The increased insulin sensitivity in growth hormone-deficient adults is reduced by growth hormone replacement therapy. European Journal of Clinical Investigation 200030 771-778. (doi:10.1046/j.1365-2362.2000.00695.x)

38 Gaillard RC, Mattsson AF, Akerblad AC, Bengtsson BA, Cara J, FeldtRasmussen U, Koltowska-Haggstrom M, Monson JP, Saller B, Wilton P et al. Overall and cause-specific mortality in GH-deficient adults on GH replacement. European Journal of Endocrinology 2012166 1069-1077. (doi:10.1530/EJE-11-1028)

39 van Bunderen C, van den Dries C, Heymans M, Franken A, Koppeschaar H, Van der Lely A \& Drent M. Effect of long-term GH replacement therapy on cardiovascular outcomes in isolated GH deficiency compared to multiple pituitary hormone deficiencies: a sub-analysis from the Dutch National Registry of Growth Hormone Treatment in Adults. European Journal of Endocrinology 2014171 151-160. (doi:10.1530/EJE-14-0069)

Received 24 June 2014

Revised version received 9 September 2014

Accepted 16 September 2014 